\title{
State regulation and public marketing of the tourism industry: environmental aspect
}

\author{
Olena Uhodnikova ${ }^{1, *}$, Viktoriya Svitlichna ${ }^{1}$, Svitlana Aleksandrova ${ }^{1}$, and Sofiia Kravtsova $^{1}$ \\ ${ }^{1}$ O.M. Beketov National University of Urban Economy in Kharkiv, Department of Tourism and \\ Hospitality, 17 Marshal Bazhanov Str., Kharkiv, 61002, Ukraine
}

\begin{abstract}
The article is devoted to the topical issues of finding ways to get the tourism industry out of the crisis at the world and national levels. In the context of the coronavirus pandemic, due to the closure of borders and a decrease in the level of income of the population, the tourism industry has suffered the greatest losses, as evidenced by the indicators of reducing the tourist flow and, accordingly, income from conducting tourist activities. Since the industry is of great socio-economic importance through providing the population with jobs and making a significant contribution to national and local budgets, as well as influencing the development of related sectors of the economy, the problem of tourism development becomes of state importance, especially in the countries with a high share of income from the tourism industry in the GDP structure. A partial marketing analysis of the issue of forming interesting tourist offers for the quarantine period was carried out. The results of a sociological survey conducted in an online format are presented in the article. These results showed the relevance of the issue of developing domestic ecotourism. Also, the article develops an algorithm for state support of the tourism industry by providing opportunities for tourist enterprises to work in the system of domestic ecotourism, which will contribute not only to the ability of tourist enterprises to continue their activities, but also have positive socio-economic and environmental consequences, in particular to ensure the sustainable development of territories through the development of ecotourism.
\end{abstract}

\section{Introduction}

Due to the introduction of quarantine measures during the coronavirus pandemic in 2020, the tourism industry experienced significant difficulties. The market for providing tourist services has decreased by almost $70 \%$. According to preliminary estimates, the losses of the tourism industry will amount to more than 1 trillion US dollars, which is noted in the report of the Organization for Economic Cooperation and Development [1]. Such a crisis has no analogues in the history of the development of the tourism industry. The projection of a pessimistic scenario for the development of quarantine restrictions allows us to calculate that by the end of the year, the losses of the tourism industry will increase to 1.2 trillion US

*Corresponding author: ugodnikova16@gmail.com 
dollars, and the volume of decline in financial and economic indicators of the tourism industry will amount to $80 \%$. In addition to the economic consequences for the tourism industry itself, such a reduction in indicators will lead to serious socio-economic consequences of a global nature. A particularly large socio-economic burden will be observed in the countries where the tourism industry occupies a significant share of GDP, in particular in a number of countries this figure reaches $20 \%$ [2]. Negative trends in tourism development will also have an impact on employment and unemployment indicators. In the pre-quarantine period, every tenth inhabitant of the planet worked in the tourism industry. According to various forecasts, between 100 and 120 million people may lose their jobs today. If we calculate this indicator taking into account the sphere of hotel and restaurant business - more than 140 million [3]. Such negative trends indicate the need to find new forms of work for the tourism industry in the context of a pandemic. An important issue is the reformatting of the work of tourist enterprises to quarantine conditions, as well as the development of state support programs for the industry in order to ensure minimal socio-economic losses at the macroeconomic and global level.

\section{Analysis of the latest researches and publications}

The issue of development of the tourism industry in the context of a pandemic is of high relevance not only from the point of view of opportunities and prospects of the tourism market itself, but also of important socio-economic importance, taking into account the impact of the industry on world GDP, other sectors of the economy (hotel and restaurant business, transport, trade, etc.), as well as social indicators of the development of society the level of employment and unemployment, tolerance, education, etc. Consequently, the high relevance and practical significance of the development of the tourism industry attract the attention of world experts to it. The main trends and tendencies of the industry are tracked and analyzed by the Organization for Economic Co-operation and Development [1], the World Travel and Tourism Council [2], the UNO [3], the World Tourism Organization [4], the European Travel Commission [5], the European Travel and Tourism Advisory Group [6] and other public and interstate organizations and associations at the global and national levels. Issues of ensuring sustainable and safe development of the tourism industry were studied by Uhodnikova O. I., Viatkin K. I., Kolesnyk T. N. [7]. The issues of ecotourism development are described in the article Liangping Wu,Guiwu Wei, Jiang $\mathrm{Wu}$ and Cun Wei Int. J. [8]. Some aspects of ecotourism are considered in the research of E. L. Farafontova, E. S. Shcheblyakov, S. M. Kurbatova, A. A. Kuzhleva and D. V. Rakhinsky [8]. However, the uncertainty caused by the danger of repeating the lockout and lockdown of quarantine measures and their impact on the tourism industry requires further research on the development of tourism in the context of global challenges of the global pandemic and environmental problems.

\section{Purposes and objectives}

Analyzing global challenges and trends in the development of tourism in the world, it is advisable to search for effective public administration mechanisms and to develop new marketing strategies for the development of the tourism industry in order to overcome the consequences of the pandemic and preserve the industry.

In accordance with the outlined goal, the following research objectives are defined and implemented:

- to analyze trends in the development of the tourism industry in the context of a pandemic, 
- to identify the ways of state support for the tourism industry at the global and local levels,

- to develop marketing approaches to switching to new tourist offers in the context of a pandemic,

- to determine the prospects for the development of the tourism industry, taking into account the implementation of the proposed measures.

\section{Statement of basic materials}

In 2020, the tourism industry began operating in the context of a global pandemic for the first time in the history of the industry's development. The tourism industry is very dependent on external factors. Socio-economic and political crises, military conflicts, and the terrorist threat have always negatively affected the development of the industry. However, they were mostly local in nature, in which tourist flows from one territory that was exposed to negative environmental factors were reoriented to other territories. The current situation can only be compared with the situation of the early twentieth century, when the Spanish flu epidemic and the fighting of the First World War practically became a new challenge for society. However, due to the low degree of development of the tourism industry at that time, it was impossible to talk about such high socio-economic consequences as now. Before the coronavirus pandemic, every tenth inhabitant of the planet worked in the tourism industry. Today, more than 100 million people have lost their jobs, and those who remain in the industry receive significantly lower salaries. The situation is no less negative in related industries that are close to tourism, in particular the hotel and restaurant business, and air travel. Now, all air carriers continue to meet their financial obligations only thanks to reserve funds. However, if there is no demand, most of them will be forced to declare bankruptcy. So, according to the World Agency Bloomberg, the prospects for bankruptcy are real for the largest airline in South America, the aviation conglomerate Airlines Group, the state-owned airline TAME (Ecuador) - primarily due to the complete lockdown of flights introduced by the United States of America, South African Express, UK domestic market airline Flybe, Virgin Australia Airlines (Australia), Air Italy (Italy), AtlasGlobal (Middle East and Caucasus region), Bek Air (Casastan), Asharami Synergy (countries of Africa), Aigle Azur (flights from Europe to Africa) and others [10]. So, analyzing the issue of airline bankruptcy, we see that this problem is global in nature and has covered all regions of the world.

The number of tourist arrivals in 2020 has significantly decreased. Therefore, in 2019, the World Tourism Organization identified the top countries by the number of tourist arrivals - fig. 1 . The diagram - fig. 1 shows statistical data on the number of arrivals in 2019 and for comparison the forecasts of their reduction in 2020 [4-9].

Based on the analysis of the diagram in Fig.1 it can be determined that the reduction of tourist flows at the global level can range from 60 to $80 \%$ according to various calculations. It all depends on the indicators of October-December, when a seasonal flu outbreak will add to the coronavirus pandemic, which may lead to the resumption of strict quarantine restrictions and a new transition to total quarantine with border closures.

According to the forecasts of the representatives of the World Tourism Organization, global GDP during the pandemic due to the reduction of tourist flows may lose from 1.5 to $2.8 \%$, which will most significantly affect the countries with a high share of the tourism industry in the structure of the country's GDP. Accordingly, analyzing tourist flows and revenues from the tourism industry in 2019 , we can make forecasts regarding the reduction of revenues from the tourism industry in 2020, depending on pessimistic, realistic and optimistic development scenarios. According to experts [1-5], depending on whether there 
will be a new lockdown of the industry or a lockdown for the population of individual countries, the following income indicators can be predicted - Table 1.

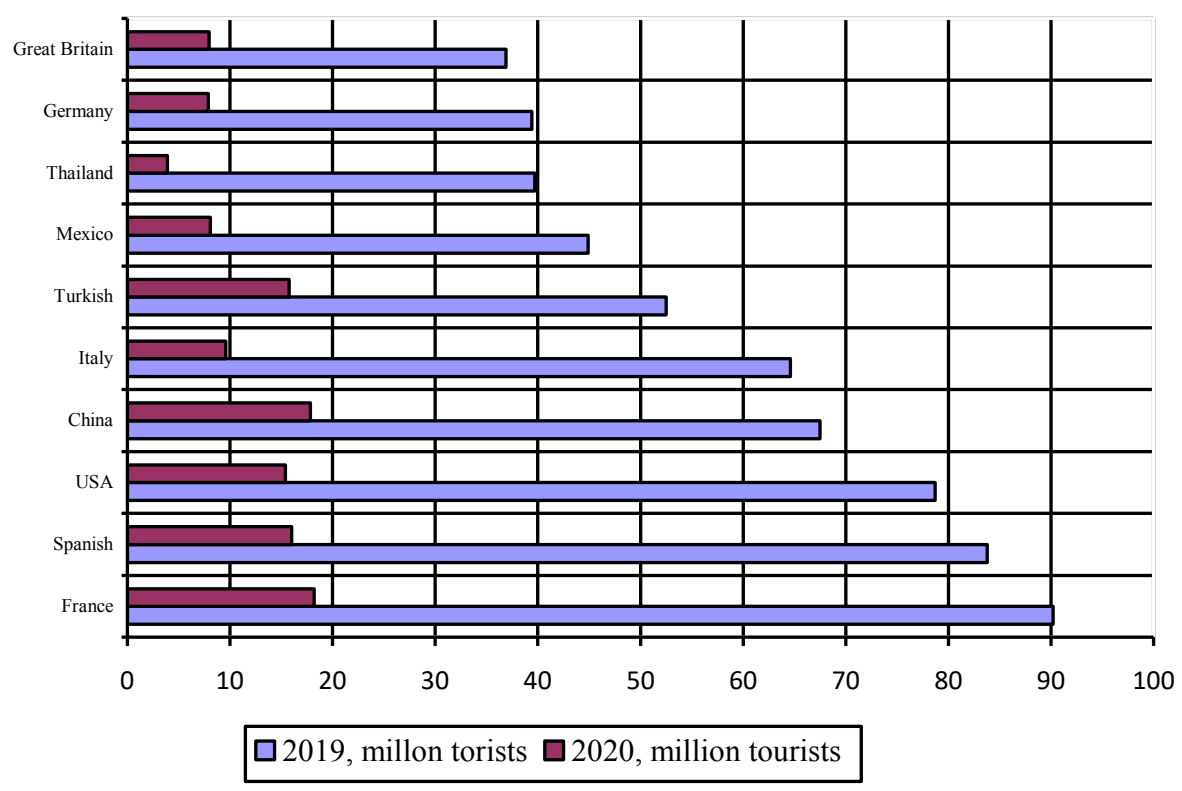

Fig. 1. Trends in changes in tourist flows of international tourism, 2019 - forecast for 2020, million persons.

Thus, based on the results of the analysis of static data on the development of the tourism industry in 2019, as well as forecast data on the reduction of the main indicators of the development of the industry, a projection of three scenarios (optimistic, pessimistic and realistic) was made regarding trends in changes in tourist flows and income from them, as well as the impact of these indicators on the formation of world GDP [6]. The results indicate high losses from the lockdown of the tourism industry in the context of the pandemic and the need to find ways to minimize these losses in order to prevent the bankruptcy of tourist enterprises, as well as minimize negative socio-economic consequences.

Table 1. Forecasts of tourism industry profitability in 2020 (developed by the authors).

\begin{tabular}{|c|c|c|c|}
\hline Scenario & $\begin{array}{c}\text { \% of tourist flow } \\
\text { reduction }\end{array}$ & $\begin{array}{c}\text { Reduction of tourism industry } \\
\text { revenues }\end{array}$ & $\begin{array}{c}\text { Global GDP } \\
\text { contraction }\end{array}$ \\
\hline Pessimistic & $80 \%$ & 1,200 billion US dollars - & 2.8 \\
\hline Realistic & $60 \%$ & 900 billion US dollars - & 2.15 \\
\hline Optimistic & $30 \%$ & 450 billion US dollars - & 1.5 \\
\hline
\end{tabular}

The main reason for the reduction of tourist flows is the introduction of barriers by states and bans on crossing borders. Experts predict a revival of the tourism market and the opening of borders in the third and fourth quarters of 2021 according to an optimistic scenario [3]. A number of experts predict the lifting of restrictions no earlier than in 2022 [2]. Therefore, in order to ensure the financial stability of tourism enterprises until the resumption of tourist flows outside the state, it is advisable to consider the possibility of developing domestic tourism.

Among the advantages of developing domestic tourism, the following can be identified: 
- revenues from the tourism industry remain entirely within the same state, both from tour operator and travel agent activities, and at the cost of expenses incurred by tourists directly during a trip,

- the development of domestic tourism contributes to the development of tourist infrastructure within the state,

- the development of domestic tourism involves attracting more local people to work in the tourism sector, that is, reducing the unemployment rate,

- domestic tourism contributes to raising the educational and cultural level of the population, awareness of their own history, traditions and ethnographic features,

- domestic tourism is more environmentally friendly, because local crossings have less impact on environmental pollution.

An important aspect of people's stay in quarantine conditions is their restrictions on the possibility of contact with nature, walking, and staying in the fresh air, since the lockdown quarantine restrictions provided for the possibility of people to go outside only for the purpose of visiting a doctor, buying food, and for work purposes. Thus, people felt the need to contact nature. In order to determine the motives of people's travel in the period after the complete lockdown, a sociological survey of Ukrainian residents was conducted by attracting social media resources. To form a marketing offer for a new travel product in the context of a pandemic, the target audience of the survey was determined to analyze their motives and travel goals. The characteristics of the target audience of the survey are presented in Table 2 .

Table 2. Characteristics of the target audience of a sociological survey conducted by the authors.

\begin{tabular}{|l|l|}
\hline Characteristics & Indicators \\
\hline Age & $22-65$ \\
\hline Income level & from 500 to 2200 US dollars per month \\
\hline $\begin{array}{l}\text { Number of trips made per year in the pre- } \\
\text { quarantine period }\end{array}$ & $1-3$ \\
\hline Average cost per trip per person & from 400 to 1000 US dollars \\
\hline Citizenship & Ukraine \\
\hline
\end{tabular}

This target audience was interviewed by distributing the questionnaire developed by the authors through social media resources in order to determine the motives of travel of Ukrainians and possible expenses during travel. The results of the survey are shown in Fig. $2,3,4$.

Therefore, based on the results of the diagram in fig. 2 we see that most tourists will choose to stay in nature and improve their health among their travel motives.

Therefore, according to the results of a sociological survey, the marketing structure of a tourist product potentially interesting for consumers during the quarantine period was determined:

- advantage of domestic tourism products,

- local going out into nature for the purpose of health improvement and recreation,

- the cost of a tourist trip is from 200 to 800 US dollars for 2 people for 5 days of rest.

Therefore, in the context of continuing quarantine measures and barriers to the development of international tourism, as well as a decrease in the level of income of the population due to the pandemic, it is advisable for the development of the tourism industry to determine the domestic tourist market with the positioning of ecotourism.

The issue of ecotourism is not only highly relevant in quarantine conditions, which will allow people to visit nature more often and increase their own immunity to diseases, but also help in the fight against global problems of sustainable development:

- problems of irrational nature resource management,

- problems of environmental pollution, 
- ensuring energy efficiency,

- climate change challenges,

- formation of eco-oriented human thinking.

Thus, the development of ecotourism should become a significant impetus to solving global problems of sustainable development of mankind, and the relevance of the development of this type of tourism, due to quarantine, will help to attract additional tourist flows in the field of domestic ecotourism.

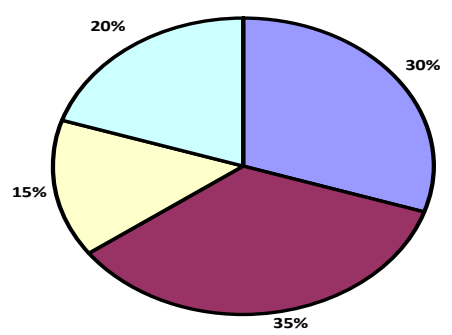

Sanitation $\square$ Staying in nature $\square$ Business tourism $\square$ Entertainment

Fig. 2. The results of a sociological survey: travel motives.

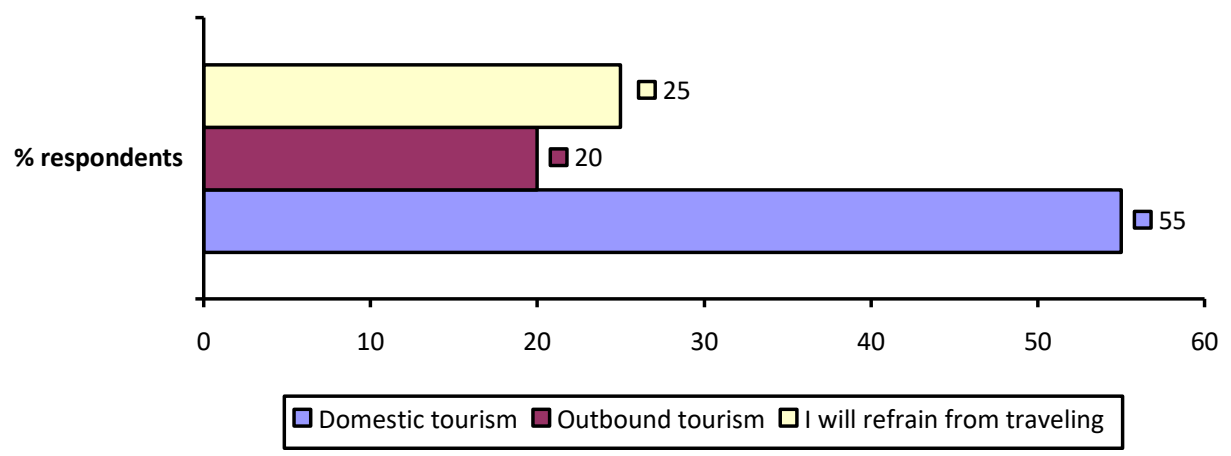

Fig. 3. The results of a sociological survey: choosing the type of tourism - domestic, outbound or abstaining from travel during the quarantine period.

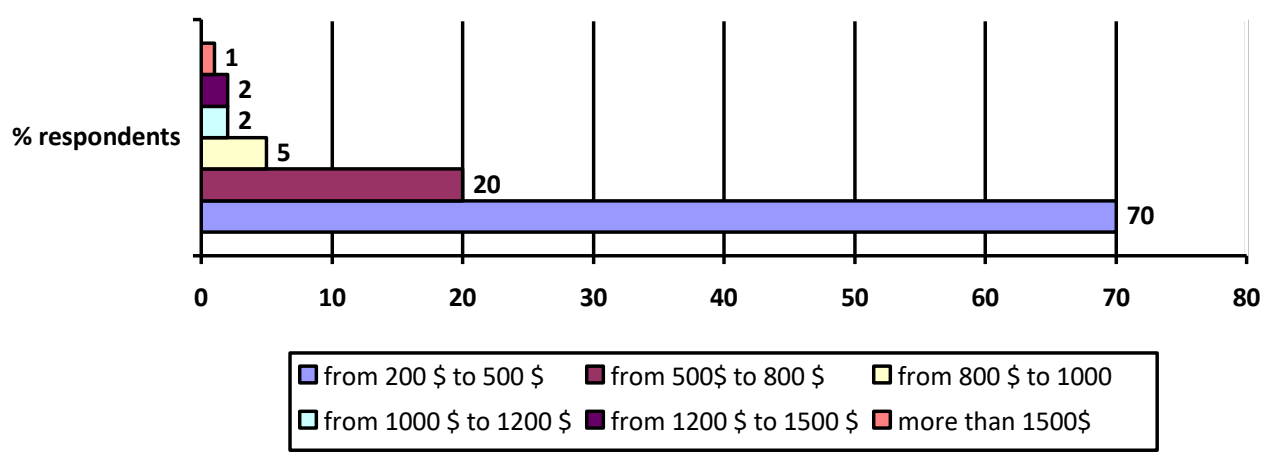

Fig. 4. The results of a sociological survey: expected travel expenses for two people for 5 days. 
The main task of the state in the context of the crisis of the tourism market and significant reductions in the financial and economic indicators of business is to provide favorable opportunities for doing business in the field of tourism, taking into account the challenges of the pandemic. To ensure state support for the tourism sector, the possibility of replenishing the state budget through the development of domestic ecotourism, the following algorithm of actions has been developed - fig. 5

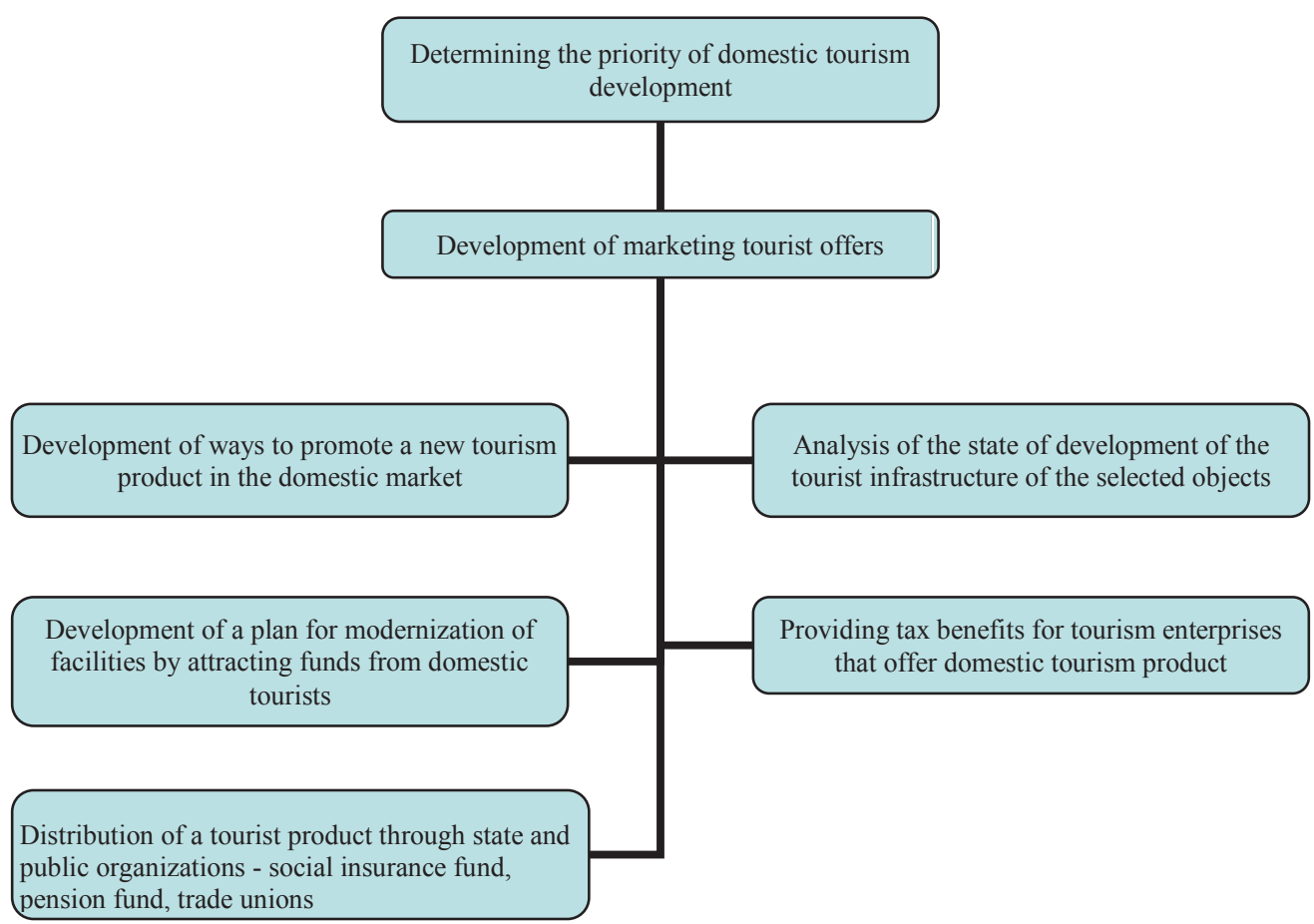

Fig. 5. Algorithm for implementing public administration measures aimed at developing domestic ecotourism in the context of a pandemic.

So, the system of state support for the tourism industry under quarantine measures should not be aimed at paying off losses of private companies or providing tax holidays, the state should provide opportunities for the tourism sector to work in the context of a pandemic, which determines the economic, marketing, technical and organizational impacts on the development of the country's tourism industry as a whole.

\section{Conclusions}

As a result of the analysis, it was determined that the coronavirus pandemic has significantly reduced the main financial and economic indicators of tourism development. The article examines an optimistic, pessimistic and realistic scenario for the development of the industry, based on statistics from previous periods and forecasts of experts of the World Tourism Organization. In particular, the losses from the decline in the number of tourist flows and revenues in the tourism industry may amount to up to $2.8 \%$ of global GDP, and experts expect a revival of the market for providing tourist services no earlier than in the third quarter of 2020. Therefore, in these conditions, it is necessary to look for effective mechanisms for continuing the work of the tourism industry in the context of a pandemic. The article presents the results of a sociological survey of Ukrainians in order to use them in marketing analysis on the formation of new tourist offers in the context of a pandemic. 
The results of the survey are the development of a proposal for the development of domestic ecotourism, which has not only positive socio-economic consequences, but also high relevance in the context of the aggravation of environmental problems of humanity. The algorithm of possible state participation in ensuring the development of eco-tourism in the domestic market is defined, which should ensure the activation of travel companies, increase state budget revenues, minimize the risks of increasing unemployment, and implement a positive impact on the environment.

\section{References}

1. Pre-OECD Ministerial Council Meeting Talks, Where are we Today and What's Next? official website Organisation for Economic Co-operation and Development. http://video.oecd.org/7072/or/Pre-OECD-Ministerial-Council-Meeting-Talks-Whereare-we-Today-and-What-s-Next-.html

2. Safe Travels: Global Protocols \& Stamp for the New Normal, official website The World Travel and Tourism Council. https://wttc.org/COVID-19/Safe-Travels-GlobalProtocols-Stamp

3. Devastated by pandemic, tourism sector must be rebuilt in a safe, equitable and climate friendly way, UN chief, UN News, official website. https://news.un.org/en/story/2020/08/1070902

4. World Tourism Organizatio, official website, http://www2.unwto.org/en

5. European Travel Commission, official website https://www.etc-corporate.org/.

6. European Travel\&Tourism Advisory Group, official website https:// www.eteg-forum

7. O.I. Uhodnikova, K.I. Viatkin, T.N. Kolesnyk, Public administration's mechanisms of the security management in tourism industry (Chernigiv. ChNTY, 2018) DOI: 10.25140/2410-9576-2018-4(16)-39-46

8. L. Wu, G. Wei, J. Wu, C. Wei, Some Interval-Valued Intuitionistic Fuzzy Dombi Heronian Mean Operators and their Application for Evaluating the Ecological Value of Forest Ecological Tourism Demonstration Areas, Int. J. Environ. Res. Public Health 17(3), 829 (2020) https://doi.org/10.3390/ijerph17030829

9. E.L. Farafontova, et.al. Problems of environmental protection in the aspect of ecological tourism, IOP Conference Series: Earth and Environmental Science 548, Environmental Engineering and Management, Mining and Soil Treatment Technology

10. Bloomberg Billionaires Index, official website, Bloomberg https://www.bloomberg.com/billionaires/ 